\title{
Mating system and pollen gene flow in Mediterranean maritime pine
}

\author{
AI de-Lucas ${ }^{1,4}$, JJ Robledo-Arnuncio², E Hidalgo ${ }^{1,4}$ and SC González-Martínez ${ }^{3,4}$ \\ ${ }^{1}$ Departamento de Producción Vegetal y Recursos Forestales, ETS Ingenierías Agrarias, Universidad de Valladolid, Palencia, Spain; \\ ${ }^{2}$ Laboratoire Génétique et Environnement, Institut des Sciences de l'Evolution, Université de Montpellier II, Montpellier Cedex, France; \\ ${ }^{3}$ Departamento de Sistemas y Recursos Forestales, CIFOR-INIA, Madrid, Spain and ${ }^{4}$ Unidad Mixta UVa-INIA, Madrid, Spain
}

\begin{abstract}
Mating systems define the mode of gene transmission across generations, helping to determine the amount and distribution of genetic variation within and among populations of plant species. A hierarchical analysis of Mediterranean maritime pine mating system (61 mother trees from 24 plots, clustered in three populations) was used to identify factors affecting mating patterns and to fit pollen dispersal kernels. Levels of ovule and seed abortion, multi- and single-locus outcrossing rates and correlated paternity were estimated from progeny arrays and correlated with ecological stand variables and biometric tree measures. Pollen dispersal kernels were fitted using TwoGener and KinDist indirect methods and simulations were carried out to identify relevant factors affecting correlated paternity. Maritime pine showed high outcrossing rates $\left(t_{\mathrm{m}}\right.$ and $\left.t_{\mathrm{s}} \sim 0.96\right)$ and relatively low levels of correlated paternity [an $r_{\mathrm{p}}$ of 0.018 (Ritland's estimate) or 0.048 (Hardy's estimate)], although higher than in other anemophilous tree species. Mating system parameters had high variation at the single-tree level (99-100\%) but no stand or population
\end{abstract}

effect was detected. At the single-tree level, outcrossing rates were correlated with tree (diameter and height) and crown size. In addition, correlated paternity showed a significant negative correlation with tree height, height to crown base and height to the largest crown width, probably reflecting the importance of the trees' 'ecological neighborhoods'. Indirectly estimated pollen dispersal kernels were very leptokurtic (exponential-power distributions with $\beta \ll 0.5$ ), with mean dispersal distances from 78.4 to $174.4 \mathrm{~m}$. Fitted dispersal kernels will be useful in building explicit simulation models that include dispersal functions, and which will contribute to current conservation and management programs for maritime pine. Nevertheless, the numerical simulations showed that restricted dispersal, male fertility and phenological overlap could only partially explain the observed levels of correlated paternity; so other factors may also be relevant for the management of this valuable forest tree species.

Heredity (2008) 100, 390-399; doi:10.1038/sj.hdy.6801090; published online 23 January 2008

Keywords: outcrossing rates; correlated paternity; pollen dispersal; KinDist; Pinus pinaster, Mediterranean forest

\section{Introduction}

Knowledge of mating systems and gene dispersal and the scale at which they operate is essential to understand the genetic structure of plant populations. They define the mode of gene transmission across generations through sexual reproduction and affect the amount and distribution of genetic variation within and among populations of plant species, including their inbreeding levels. Mating system and gene dispersal also influence effective population sizes and the degree to which populations subdivide due to selection or genetic drift (Schoen and Brown, 1991; Holsinger, 2000; Glémin et al., 2006). Traditionally, only outcrossing rates were considered in mating system studies but other parameters are also of major importance. For instance, correlated paternity (that is, the proportion of full sibs within maternal progeny arrays), when combined with restricted dispersal, may enhance fine-scale genetic structure, kin competition and,

Correspondence: AI de-Lucas, Departamento de Producción Vegetal y Recursos Forestales, ETS Ingenierías Agrarias, Universidad de Valladolid, Avenida de Madrid 44, Palencia 34004, Spain.

E-mail:ailucas@pvs.uva.es

Received 12 July 2007; revised 26 November 2007; accepted 26 November 2007; published online 23 January 2008 ultimately, levels of biparental inbreeding (that is, mating among relatives) and inbreeding depression in subsequent generations (for example, Griffin and Eckert, 2003; Degen et al., 2004). Moreover, correlated paternity estimates can provide powerful insights into pollination biology (for example, Hardy et al., 2004; Verdú et al., 2006).

Multiple ecological factors and demography affect mating patterns in plant populations. At the stand and population level, mating patterns are affected by natural factors such as population density and size, mode of pollination, flowering synchrony and phenological patterns (El-Kassaby and Jaquish, 1996; Robledo-Arnuncio et al., 2004a; Gérard et al., 2006; O'Connell et al., 2006), as well as management and silvicultural practices (Murawski et al., 1994; El-Kassaby et al., 2003). At the individual level, plant size and shape (in particular crown shape in trees), gender expression, male and female reproductive effort and within-stand social position can also affect mating patterns (Burczyk et al., 1996, 2002; Dow and Ashley, 1998; O'Connell et al., 2004; García et al., 2005; Verdú et al., 2006). Forest trees typically have a low level of domestication, and management strategies in forest tree breeding programs, in situ conservation units or ex situ conservation plantations often rely on open pollination. Thus, identifying the 
precise factors affecting the mating system, as well as investigating their relative importance and the scale at which they operate (population, stand and individual), is of great importance. For instance, seed orchard design in forest trees relies on spatial location of trees to prevent inbreeding and can benefit from estimation of mating system parameters, such as outcrossing rates or levels of correlated paternity and their variation with spatial scale.

A determinant process in plant mating systems is the spatial pattern of pollen dispersal. Direct and indirect approaches based on molecular markers are now commonly used to describe contemporary pollen dispersal movement (see reviews in Adams and Burczyk, 2000; Smouse and Sork, 2004; Smouse and RobledoArnuncio, 2005; Sork and Smouse, 2006). Direct methods are usually based on paternity analysis, while indirect methods derive pollen dispersal estimates from the observed pollen pool genetic structure under different assumptions. Paternity-based analysis can identify precisely individual pollen donors (at least a portion of them) for each maternal progeny, describe the shape of the dispersal curve (generally at short distances) and estimate the proportion of pollen immigration into a delimited area (for example, Burczyk et al., 1996, 2002; Smouse et al., 1999; Schuster and Mitton, 2000). This method, however, requires complete sampling of potential fathers within the study area and high genetic resolution, which generally restricts inferences to estimates of short-distance pollen gene movement (see reviews above). The spatial scale limitation of paternity-based methods is a major drawback, since longdistance gene dispersal may have a higher impact on population genetic structure and patterns of colonization than short-distance pollen movements. For instance, Klein et al. (2006) recently showed that fat-tailed dispersal kernels led to diverse propagule pools and colonization waves of increasing speed, being the shape of the dispersal kernel tail (thinner or fatter than an exponential) the sole determinant of alternative migration models (island vs stepping stone models) and more relevant than average dispersal distances. In comparison with paternity analysis, indirect methods do not require sampling potential pollen donors and can thus, for a given sampling effort, recover information from a broader spatial scale. For this reason, indirect methods, such as TwoGener (Smouse et al., 2001; Austerlitz and Smouse, 2001, 2002) and KinDist (Robledo-Arnuncio et al., 2006), are specially suited for pollen dispersal studies within large, continuous and dense populations of plants.

Maritime (or cluster) pine (Pinus pinaster Aiton) is a keystone southwestern Mediterranean forest tree with a surprisingly ample ecological niche: it grows in regions with annual rainfall from as low as $350 \mathrm{~mm}$ (Oria, southern Spain) to over $1300 \mathrm{~mm}$ (Corsica), in different soil types (for example, acid sandy soils in the Castilian Plateau or limestone in Segura-Alcaraz mountains in southeastern Spain) and at different altitudes, from sea level to $1900 \mathrm{~m}$ (in the Moroccan High Atlas mountains). Common garden experiments and characterization of natural populations of maritime pine have shown a remarkable phenotypic and genetic variability in growth and life-story traits among populations (Alía et al., 1995, 1997; Tapias et al., 2004; Chambel, 2006). Maritime pine is also one of the most important commercial tree species in southwestern Europe. For instance, in Spain, maritime pine represents over $10 \%$ of the forest cover, including more than 600000 ha of plantations, with wood stocks of $\sim 58000 \mathrm{~m}^{3}$, which make maritime pine the leading commercial species in terms of cuttings, well over other important Iberian pine crops such as Scots or Black pine.

Despite the relatively wide distribution of Mediterranean maritime pine (over 724000 ha of native forest in the Iberian Peninsula), several natural relict populations, potentially harboring valuable genetic resources, are threatened by recurrent wildfires favoring replacement by other species (such as $P$. halepensis Mill), pollen immigration from plantations of extraneous origin, overexploitation and lack of natural regeneration. These features make maritime pine the object of conservation programs that are also designed to be compatible with the use of its breeding resources (Bucci et al., 2007).

Evidence of fine-scale genetic structure up to $\sim 30 \mathrm{~m}$ and restricted seed and seedling dispersal (average dispersal distance of $\sim 10-20$ and $\sim 40-60 \mathrm{~m}$, respectively) has been found in Mediterranean maritime pine (González-Martínez et al., 2002, 2006; Nanos et al., 2004). However, these studies were based on a single population (Coca, Segovia, in central Spain) and their results could vary for other populations or at different spatial scales within the same population. Knowledge of mating system variation and its causal factors within broad provenance regions is relevant for definition of homogenous breeding or conservation units. Therefore, the goals of this study are (1) to estimate rates of unfertilized ovules (UO) and aborted seeds (AS), outcrossing rates, biparental inbreeding and correlated paternity in maritime pine at different spatial scales (population, stand and individual) within a typical maritime pine provenance region in eastern Spain, (2) to investigate ecological factors (altitude, slope, exposure, density and forest cover) and individual-tree parameters [total height (HT), height to crown base and to largest crown width (CW), diameter at $1.30 \mathrm{~m}$ and at crown base, $\mathrm{CW}$ and crown surface exposed to sun irradiation] that might affect mating patterns, including most relevant factors reported by the literature and using both observational data and numerical simulations and (3) to fit pollen dispersal kernels using indirect methods based on molecular markers (TwoGener and KinDist). In its Mediterranean range, native populations of maritime pine are scattered and often surrounded by commercial or watershed protection plantations. Estimates of pollen dispersal kernels have potential interest in defining buffer zones that would prevent immigration by pollen from plantations and the possible effects of outbreeding depression in valuable singular populations. In addition, outside its native European range, maritime pine has been reported as one of the worst 100 invasive species in the world (see http:/ / www.issg.org/database/species/ecology.asp?fr = $1 \& s i=43 \& s t s)$. In the latter context, pollen dispersal kernel estimates, alongside with estimates of seed dispersal kernels and survival probability functions, can be used to parameterize colonization models. Finally, mating system (and causal factors) estimates will improve the knowledge of maritime pine in its native range, which is relevant for its management and conservation, in particular, for control of inbreeding in conservation plantations and for development of natural regeneration silvicultural guidelines. 


\section{Materials and methods}

\section{Study area and sampling}

Mating system analysis in maritime pine was carried out in 24 stands located in the 'Serranía de Cuenca' mountains, in the east of the Iberian Peninsula (Figure 1), a typical native provenance region of the species. Native pine forests in this region are widespread, forming large continuous populations at high density (average of 800-1100 trees per hectare in the study area). In the Serranía de Cuenca mountains, maritime pine grows in sandy and low-fertility soils, often accompanied by Mediterranean shrubs and herbs, such as Erica scoparia, Phyllyrea angustifolia and Rosmarinus officinalis. Average temperature is $13{ }^{\circ} \mathrm{C}$ and annual precipitation is $550 \mathrm{~mm}$, with a pronounced drought in summer. Stands sampled were clustered in three zones or 'populations' within a continuous maritime pine forest, namely Talayuelas, Landete and Cañete, separated from each other by $15-20 \mathrm{~km}$. Geographic coordinates and stand characteristics are shown in Supplementary Table S1.

In each stand, one to six (average of 3.03) mature cones from each of one to three mother trees were randomly collected (total of 61 trees and 188 cones). Total number of seeds and percentages of UO and AS were counted for each cone. Four to 30 (average of 11.6) viable seeds were randomly selected from each of the 61 trees in order to obtain 30 evenly collected (among cones and trees) seeds per stand for genetic analyses $(N=720)$. Seeds were germinated and embryos were frozen at $-20{ }^{\circ} \mathrm{C}$ until DNA extraction. The following traits for each tree were measured: HT, stem diameter at $1.30 \mathrm{~m}(\mathrm{DBH})$, stem diameter (DCB) and height (HCB) to crown base, $\mathrm{CW}$ and height to the largest crown width (HLCW) (see Supplementary Table S2). Plant material (wood) was collected to determine mother-tree genotypes. Crown measurements (CW and HLCW) were used to compute a revolution ellipsoid surface for each tree, representing the tree crown surface exposed to sun irradiation and available for photosynthesis, which is an indicator of tree health and vigor.

\section{DNA isolation and molecular markers}

Total genomic DNA was isolated from embryos and wood following Doyle and Doyle (1990) protocol adapted by Torres et al. (1993) for small volumes. We selected three chloroplasts (Pt30204, Pt87268 and Pt1254) and three nuclear (Itph4516, Ctg275 and Ctg4363) microsatellite markers due to their high levels of polymorphism in previous wide-range studies of the species (Derory et al., 2002; Chagné et al., 2004; Bucci et al., 2007). The chloroplast is paternally inherited in pines and chloroplast-based markers allow direct identification of paternal gametes. The amplification conditions for chloroplast (Robledo-Arnuncio et al., 2004b) and nuclear (González-Martínez et al., 2002 for Itph4516 and Chagné et al., 2004 for Ctg275 and Ctg4363) microsatellites are given elsewhere. Microsatellite fragments were scored in an ABI-PRISM 310 genetic analyzer (Applied Biosystems, Foster City, CA, USA) using GeneScan ROX-500 as internal ladder and standard running parameters.

\section{Mating system and dispersal kernel estimates}

Chloroplast fragments were combined in haplotypes and treated as a single locus. Single- and multilocus estimates of outcrossing rates ( $t_{\mathrm{s}}$ and $t_{\mathrm{m}}$, respectively) were computed using either a moments (for individual trees) or a likelihood (for populations) method based only on nuclear microsatellites (see Ritland, 2002 for details). The difference between multilocus and single-locus estimates of outcrossing $\left(t_{\mathrm{m}}-t_{\mathrm{s}}\right)$ was used to estimate biparental inbreeding (that is inbreeding due to mating among relatives). Two different methods were used to calculate correlated paternity within maternal progenies $\left(r_{\mathrm{p}}\right)$ using both nuclear and chloroplast microsatellites: (1) a kinship method based on co-ancestry among inferred pollen gametes within families (see Hardy et al., 2004 for details) and (2) a maximum-likelihood multilocus method (Ritland, 2002), fixing selfing to 0 (in order to force the inclusion of selfed seeds in the calculation of $r_{\mathrm{p}}$ as in Hardy's method). Ritland's $r_{\mathrm{p}}$ estimate has been shown to underestimate correlated paternity, in particular for parametric values of $r_{\mathrm{p}}<0.15$ (Hardy et al., 2004); nevertheless, it is useful for comparative purposes with other published studies. Equal allele frequencies among families in the same population were assumed. Correlated paternity $\left(r_{\mathrm{p}}\right)$ was computed separately for chloroplast and nuclear markers and averaged. Variance components (populations, stands within populations

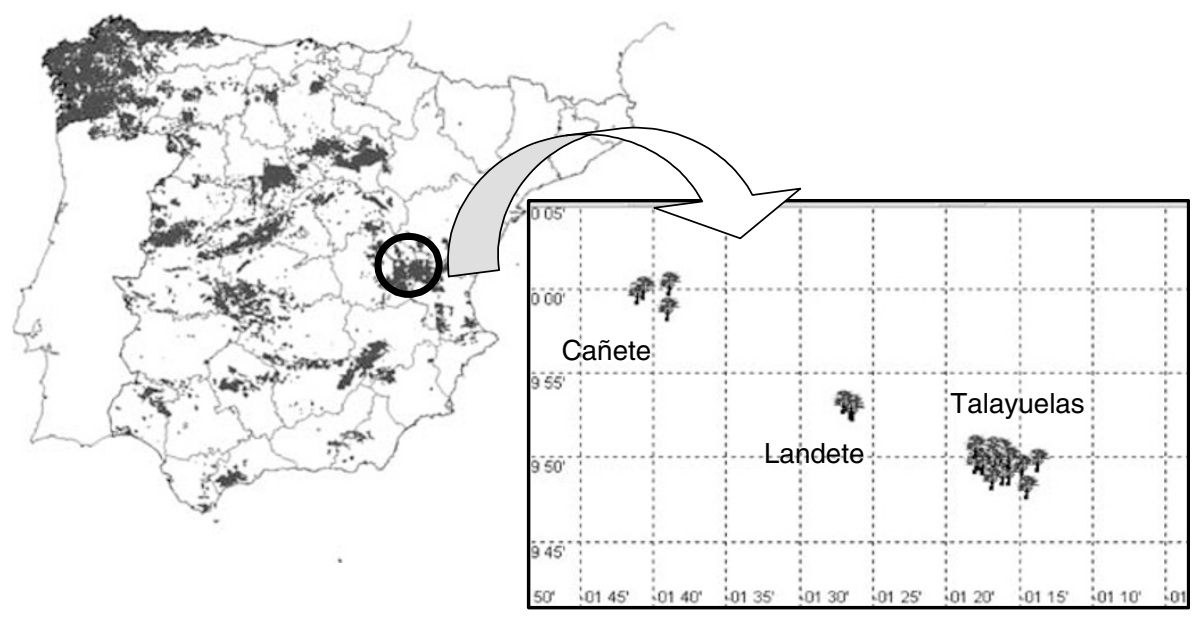

Figure 1 Location map of populations and stands within populations. Two to three mother trees were sampled in each stand up to a total of 61 individuals. The shadowed area represents the current range of Pinus pinaster in Spain. 
and trees within stands) were calculated for mating parameters. Analyses were carried out using MLTR ver. 3.0 (Ritland, 2002), SAS ver. 9.0 (SAS Institute Inc., NC, USA) and our own software.

Dispersal kernels of the exponential-power family (Tufto et al., 1997; Austerlitz et al., 2004) were fitted using two indirect methods based on the spatial genetic structure of the pollen pool: TwoGener (Smouse et al., 2001; Austerlitz and Smouse, 2002) and KinDist (Robledo-Arnuncio et al., 2006). The TwoGener method is based on the relationships between physical distances among a sample of mother trees and pairwise intraclass genetic correlations $\left(\Phi_{\mathrm{ft}}\right)$ for the pollen pools sampled by these mothers. To fit dispersal kernels using the TwoGener approach, an independent estimate (or a joint estimation) of $d_{\mathrm{e}}$ (the effective density of pollen donors) is needed (Austerlitz and Smouse, 2002), which can complicate the accurate estimation of two-parameter kernels. In addition, this method assumes uniformity in male fecundity and synchronous flowering. The KinDist method is based on a normalized measure of correlated paternity $(\Psi)$ between female pairs (Robledo-Arnuncio et al., 2006). The estimates of dispersal kernel parameters obtained by KinDist are generally more accurate than those from TwoGener, because KinDist does not rely on effective density, a parameter, which is very difficult to measure in the field. Joint estimation of $d_{\mathrm{e}}$ with TwoGener is associated with the usual statistical problems of increasing the dimensionality of the parameter space. The KinDist method is also robust for the levels of male fecundity variation and asynchronous flowering commonly observed in forest tree populations (RobledoArnuncio et al., 2006).

\section{Stand and individual-tree variables affecting mating parameters}

Mating system parameters (UO, AS, $t_{\mathrm{s}}, t_{\mathrm{m}}, t_{\mathrm{m}}-t_{\mathrm{s}}$ and the two estimates of $r_{\mathrm{p}}$ ) were correlated with stand (altitude, slope, exposure, density and forest cover; see Supplementary Table S1) and individual-tree (see Supplementary Table S2) variables using lineal regression. To reduce individual-tree variables to newly derived variables that summarize the original information, a principal component analysis (PCA) was carried out. A high proportion of the total variance (90.42\%) was explained by the two first components, which were related to diameter and crown (PC1; $56.26 \%$ of the variance) and height (PC2; $34.16 \%$ of the variance) variables (see details, including factor loads, in Supplementary Material). Therefore, for individual-tree analyses, mating system parameters were correlated with the original variables and these two summary PCs (PC1 and PC2).

Insights about individual-tree variables affecting correlated paternity $\left(r_{\mathrm{p}}\right)$ in maritime pine were obtained through simulation as follows. Each of 61 mother trees was generated in the center of a forest stand of $500 \times 500 \mathrm{~m}^{2}$ (25 ha) with density of 1000 trees per hectare. Coordinates of potential father trees were randomly generated imposing a minimum separation distance between trees of $2 \mathrm{~m}$. The probability of the $i$-th pollen donor to mate with the $j$-th mother $\left(\pi_{i j}\right)$ was computed using experimentally adjusted exponentialpower dispersal kernels (see above) weighted by different factors depending on the simulation set, in the form:

$$
\pi_{i j}=\frac{\lambda_{i} \varphi_{i j} p_{i j}}{\sum_{k \in N} \lambda_{k} \varphi_{k j} p_{k j}}
$$

where $p_{i j}$ is the probability of mating given by the dispersal kernel, $\lambda_{i}$ is the male fecundity of the $i$-th individual, $\varphi_{i j}$ the phenological overlapping of the $i$-th pollen donor with the $j$-th mother tree (weighted or not, depending on the simulation set, by the number of female flowers available for mating, see below) and $N$ is the total number of trees in the stand (25000). Families replicating our sampling design $(N=720$, with average family size of 11.7 offspring) were created. The proportion of full-sib pairs found within each maternal progeny arrays was counted and averaged by family for each simulation run.

One thousand runs for each set of simulations were carried out, each time recording an average $r_{\mathrm{p}}$ and among-family s.d. (based on 61 families). Simulations were carried out assuming panmixia and no differences in mating success among parent trees (to test the goodness of the method), yielding values of correlated paternity $(0.000042 \pm 0.000127$, average and s.d. of 1000 runs) that were not significantly different from expectations $(1 / 25000=0.000040)$. We considered the following scenarios: (1) The first set of simulations tested the effect of restricted pollen dispersal using exponential-power kernels with parameters: (1a) $\alpha=0.0074 ; \beta=0.2445$; $\delta=78.4 \mathrm{~m}$, the fitted kernel at Talayuelas (see 'Results'); (1c) $\alpha=0.0244 ; \beta=0.2520 ; \delta=174.4 \mathrm{~m}$, the fitted kernel at Landete and (1b) $\alpha=0.0150 ; \beta=0.2490 ; \delta=125.3 \mathrm{~m}$, an intermediate average-distance dispersal kernel. (2) The second set of simulations considered the same dispersal kernels as in scenario 1 but also included the effects of unequal male fertility. Differences in fertility among potential male parents were made proportional to tree height using an exponential function (Burczyk et al., 1996), resulting in a L-shaped fertility distribution with a coefficient of variation of $\sim 129 \%$, similar to observed values in natural populations of Mediterranean maritime pine (Miguel-Pérez et al., 2002). The height of each simulated tree was drawn from a normal distribution of average $11.90 \mathrm{~m}$ and s.d. $2.82 \mathrm{~m}$, parameters which were obtained by fitting a dataset of 3648 maritime pine tree heights (including the mother trees) measured in the study area. Finally, in sets (3) and (4) the effects of male and female flowering synchrony were added to model (2). In set (3), only overlapping of male and female flowering periods (full overlapping for synchronized trees and 20\% overlapping for trees with early or late male flowering; Miguel-Pérez et al., 2002) was considered (in a similar way to Robledo-Arnuncio et al., 2004a for Scots pine), while in set (4) flowering synchrony was simulated using a Poisson distribution to generate the number of female flowers available for mating in a given day of the flowering period (similarly to Hardy et al., 2004). Simulated phenology resulted in coefficients of variation of male mating success (other factors removed) of $\sim 65 \%$ and $\sim 99 \%$ for sets (3) and (4), respectively. Both phenological models were parameterized with male and female flowering observations in maritime pine from the Castilian Plateau made during 1999 and 2000 (Miguel-Pérez et al., 2002). 


\section{Results}

\section{Mating system and dispersal kernel estimates}

The percentages of UO and AS per tree were very variable, ranging $0.9-51.0 \%$ (but only four trees, three in Talayuelas and one in Landete, had percentages >20.0) and $0.7-16.6 \%$, respectively. Average (over populations) outcrossing rates were high $(\sim 96 \%)$ and biparental inbreeding was low (average $t_{\mathrm{m}}-t_{\mathrm{s}}=0.040$ ). Average correlated paternity $\left(r_{\mathrm{p}}\right)$ varied from 0.018 (Ritland's estimate) to 0.048 (Hardy's estimate, similar to the estimate provided by TwoGener: 0.049; data not shown), which translated to an effective number of fathers $\left(N_{\mathrm{ep}}=1 / r_{\mathrm{p}}\right)$ of $\sim 21$ or 56 (Table 1). Ritland (2002) estimate of $r_{\mathrm{p}}$ has been suggested to underestimate correlated paternity at the family level (Hardy et al., 2004), which agrees with results presented here. However, both correlated paternity estimates (Ritland's and Hardy's) were correlated (Pearson's $r$ of 0.68), in particular for $r_{\mathrm{p}}>0.07$ (Pearson's $r>$ of 0.82), a trend also reported by Hardy et al. (2004). Mating system estimates were similar in the three studied populations. Landete showed higher rates of AS and lower multilocus outcrossing rates, biparental inbreeding and correlated mating than the others, but these differences were not significant (as shown by one-way ANOVA). Hierarchical partition of the variance in population, stand and mother-tree components showed that almost all the variance $(99-100 \%)$ in the mating system parameters studied is due to differences among individual trees.

Using indirect methods based on pollen-pool spatial structure (TwoGener and KinDist), pollen dispersal kernels were fitted for Talayuelas and Landete (Figure 2). Dispersal kernels for Cañete did not converge, probably due to lack of intermediate-distance pairs in the intermother distance distribution. Parameter estimates were similar with TwoGener and KinDist methods and only results from the latter are reported here. In Talayuelas, the parameter estimates for the best fitting exponentialpower dispersal kernel were $\alpha=0.0074$ and $\beta=0.2445$, yielding an average effective pollen dispersal distance, $\delta$, of $78.4 \mathrm{~m}$. Parameter estimates in Landete were $\alpha=0.0244, \beta=0.2520$ and $\delta=174.4 \mathrm{~m}$. Normalized correlated paternity rates $(\Psi)$ between female pairs showed the theoretically expected (under restricted dispersal) negative association with distance, which was statistically significant in Talayuelas (Mantel test on ranked variables, $r=-0.16 ; P=0.019)$ but not in Landete ( $r=-0.15 ; P=0.147)$ over the distance range sampled (0-1250 m; Figure 2), maybe as a result of the smaller number of mothers sampled in the latter case (43 mother trees in Talayuelas vs 11 in Landete). A global dispersal kernel, fitted by pooling data from the tree stands and assuming constant allele frequencies across the entire area, revealed a similarly leptokurtic pollen dispersal and an average dispersal distance intermediate between Talayuelas's and Landete's $(\alpha=0.0028, \beta=0.2229$ and $\delta=111.9 \mathrm{~m})$

\section{Stand and individual-tree variables affecting mating parameters}

Lineal regression analyses among mating system parameters and stand variables showed a relatively weak albeit significant negative relationship between multilocus (adjusted $R^{2}=0.143 ; P=0.038$ ) and single-locus (adjusted $R^{2}=0.146 ; P=0.037$ ) outcrossing rates and
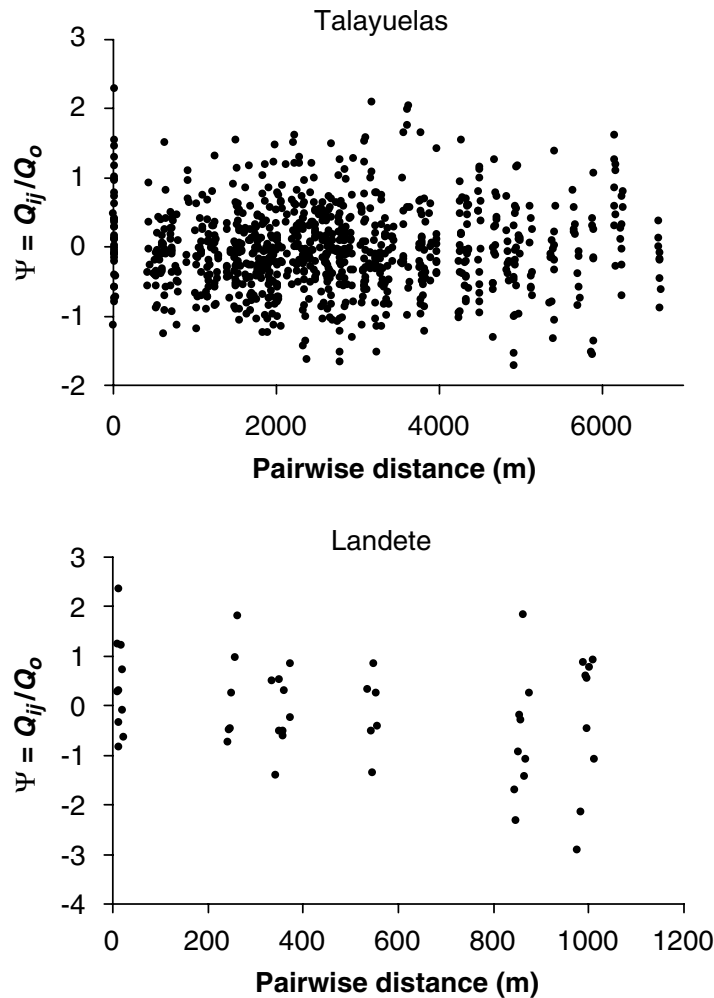

Figure 2 Relationship between pairwise normalized amongmothers correlated paternity $(\Psi)$ and distance in Talayuelas and Landete. This correlation was used to fit dispersal kernels using the KinDist approach.

Table 1 Mating system parameters in three Mediterranean maritime pine stands from eastern Iberian Peninsula

\begin{tabular}{lccccccc}
\hline Population & UO (\%) & AS (\%) & $\mathrm{t}_{s}$ & $\mathrm{t}_{m}$ & $\mathrm{t}_{m}-\mathrm{t}_{s}$ & $\mathrm{r}_{p}$ \\
\cline { 3 - 7 } & & & & & & Hardy et al. (2004) & Ritland (2002) \\
\hline Talayuelas & 8.55 & 5.10 & $0.911(0.019)$ & $0.979(0.011)$ & 0.068 & 0.057 \\
Landete & 6.46 & 6.28 & $0.941(0.043)$ & $0.951(0.040)$ & 0.010 & 0.023 & 0.033 \\
Cañete & 7.61 & 4.15 & $0.960(0.020)$ & $1.000(0.000)$ & 0.040 & 0.063 & 0.010 \\
Average (s.d.) & $7.54(1.05)$ & $5.18(1.07)$ & $0.937(0.025)$ & $0.977(0.025)$ & $0.040(0.030)$ & $0.048(0.022)$ & $0.018(0.013)$ \\
\hline
\end{tabular}

Abbreviations: AS, percentage of aborted seeds; UO, percentage of unfertilized ovules; $r_{\mathrm{p}}$, correlated mating within maternal progeny arrays; $t_{\mathrm{m}}$, multilocus outcrossing rate (bootstrap-based s.d. between parentheses); $t_{\mathrm{s}}$, single-locus outcrossing rate (bootstrap-based s.d. between parentheses); $t_{\mathrm{m}}-t_{\mathrm{s}}$, biparental inbreeding. 
density (estimated as number of trees per hectare). This significant correlation was caused by two high-density stands (1924 and 2249 trees per hectare) within Talayuelas that showed unusually low outcrossing rates $\left(t_{\mathrm{m}}\right.$ and $t_{\mathrm{s}}$ of 0.618 and 0.600 , and 0.784 and 0.790 , respectively). None of the other mating system parameters tested (UO, AS, $t_{\mathrm{m}}-t_{\mathrm{s}}$ and $r_{\mathrm{p}}$ ) showed any significant correlation with stand variables (altitude, slope, exposure, density and forest cover).

At the individual-tree level, multilocus and singlelocus outcrossing rates were positively correlated with HT (adjusted $R^{2}=0.063 ; P=0.028$ and adjusted $R^{2}=0.077 ; P=0.017$, respectively) and PC1 (adjusted $R^{2}=0.060 ; P=0.032$ and adjusted $R^{2}=0.076 ; P=0.018$, respectively), related to diameter and crown variables
(DBH, DCB and ellipsoid surface). In addition, correlated mating (as estimated by Ritland's maximum-likelihood multilocus method; similar results were obtained using Hardy's method but were not significant) was negatively correlated with PC2 (adjusted $R^{2}=0.146 ; P=0.046$ ), related to height variables (H, HCB and HLCW) (Figure 3). However, these correlations were weak and did not explain a substantial amount of the total variance (as shown by low adjusted $R^{2}$ coefficients).

Further insights on the factors affecting correlated paternity (or its inverse, the number of effective fathers) were obtained through simulation (Figure 4). Under our model assumptions, restricted pollen dispersal alone did not seem enough to produce the observed values of correlated paternity. Indeed, the relatively long spatial
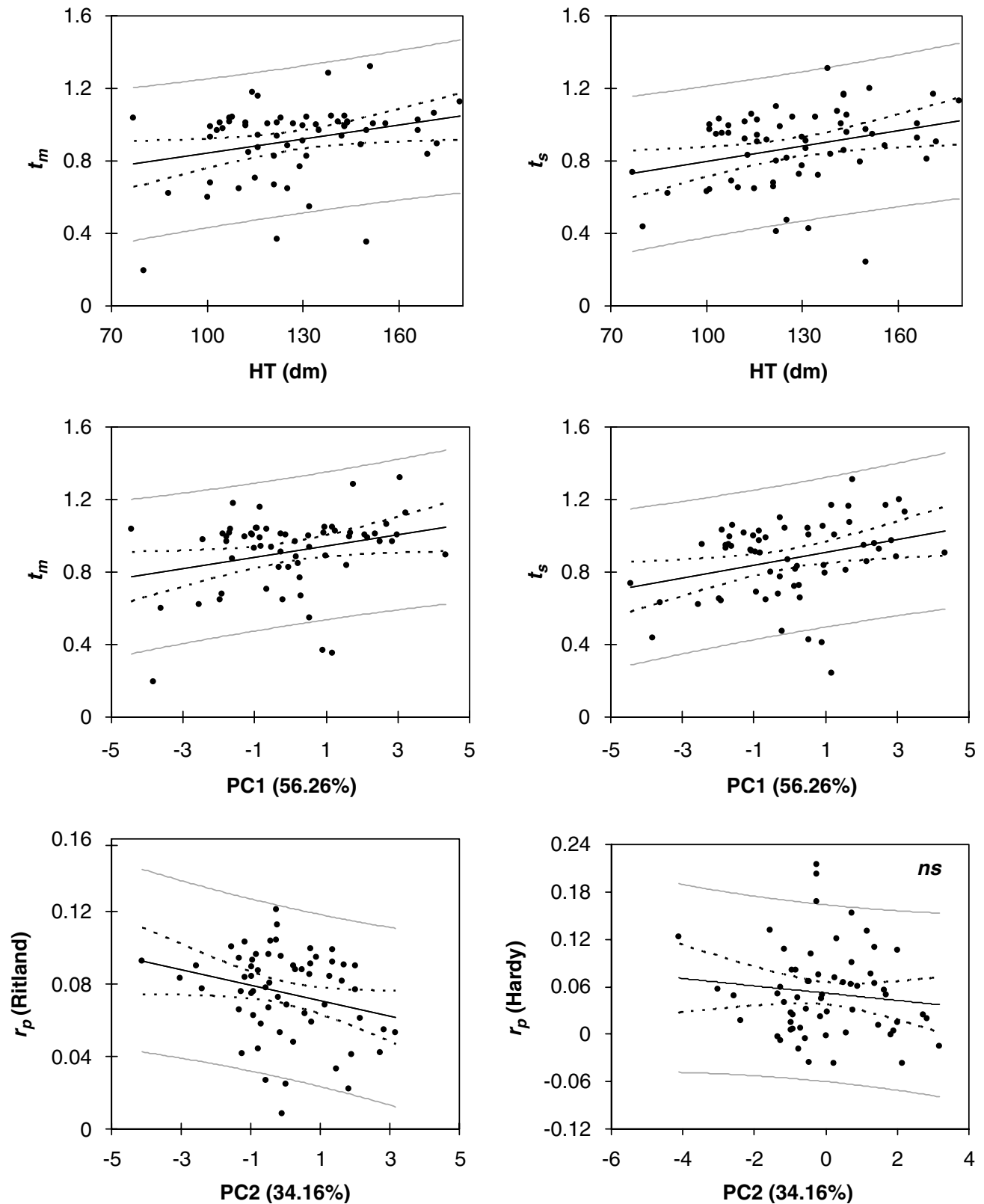

Figure 3 Scatter plots (showing also confidence intervals obtained from lineal regression) for significant mating system and individual-tree variables. HT, total height; $t_{\mathrm{s}}$, single-locus outcrossing rate; $t_{\mathrm{m}}$, multilocus outcrossing rate; $r_{\mathrm{p}}$, correlated mating within maternal progeny arrays. PC1 and PC2 are principal components related to diameter and crown (PC1; 56.26\% of the variance) and height (PC2; 34.16\% of the variance) variables (see details, including factor loads, in Supplementary Table S3). 
range of the best-fitting dispersal kernels, combined with the high population density, resulted in very low estimates of correlated paternity $(0.0026-0.0008)$ under homogeneous male fecundity and synchronous flowering. Values of $r_{p}$ closer to those observed in our study (but still lower) were only obtained when variation in male reproductive success, due to differences in fertility (estimated as proportional to tree height using an exponential function), and phenological overlapping were added to the simulations [0.0120-0.0037 for set (3) and 0.0160-0.0052 for set (4); Figure 4].

\section{Discussion}

In the dense, continous forests of the Serranía de Cuenca (east of the Iberian Peninsula), the maritime pine mating system is characterized by high outcrossing rates $(\sim 96 \%)$, relatively low levels of correlated paternity $\left(r_{\mathrm{p}}=0.018\right.$ or $0.048 ; N_{\mathrm{ep}}=1 / r_{\mathrm{p}}$ of 21 or 56$)$ and biparental inbreeding (average $t_{\mathrm{m}}-t_{\mathrm{s}}=0.040$ ). High outcrossing rates (multi- and single-locus) are common in conifer species, in particular pines (see Burczyk et al., 1996 and references therein; Boshier, 2000 and, more recently, Wasieliwska et al., 2005). However, the effective number of fathers estimated in maritime pine is lower than values reported in most wind-pollinated conifers growing at high densities (83-125 in P. sylvestris; RobledoArnuncio et al., 2004b; 62-143 in Picea glauca, O'Connell et al., 2006; see also reviews in Smouse and Sork, 2004; Hardy et al., 2004) and only slighter higher than in Larix occidentalis ( 10-16 at densities of 240-940 trees per hectare inside a mixed stand of 1200 trees per hectare; El-Kassaby and Jaquish, 1996). El-Kassaby and Jaquish (1996) found correlated mating in high-density natural populations five times higher than in low-density seed tree stands and suggested that the lower density of potential pollen donors can be compensated by longerrange pollen movement in open populations. A relatively low level of correlated mating and biparental inbreeding agrees with previous studies showing weak albeit significant fine-scale genetic structure in maritime pine (González-Martínez et al., 2002; Nanos et al., 2004).

Variation in maritime pine mating system parameters (UO, AS, $t_{\mathrm{m}}, t_{\mathrm{s}}, t_{\mathrm{m}}-t_{\mathrm{s}}$ and $r_{\mathrm{p}}$ ) was not explained by any stand or population variable. A significant negative correlation was found between tree density and outcrossing rates but it was caused by only two 'outlier' stands growing at very high densities ( $\sim 2000$ trees per hectare) that showed unsually low outcrossing rates. This result might be explained by the lower crown and smaller size (DBH of $19.1 \mathrm{~cm}$ and HT of $8.96 \mathrm{~m}$, compared to averages of $22.7 \mathrm{~cm}$ and $13.11 \mathrm{~m}$, respectively) observable in these pine trees growing at high densities and the positive correlation between tree (and crown) size and outcrossing rate at the individual level (see 'Results' and the discussion below).

Plant density is expected to greatly influence mating patterns (Farris and Mitton, 1984; Burdon et al., 1988; Wolff et al., 1988; Murawski et al., 1994; Van Treuren et al., 1994; Franceschinelli and Bawa, 2000). However, there is not a clear trend in the relationship between density and outcrossing rates, at least in conifers species. Positive relationships between multilocus and single-locus outcrossing rates and density have been found for P. ponderosa (Farris and Mitton, 1984), L. laricina (Knowles

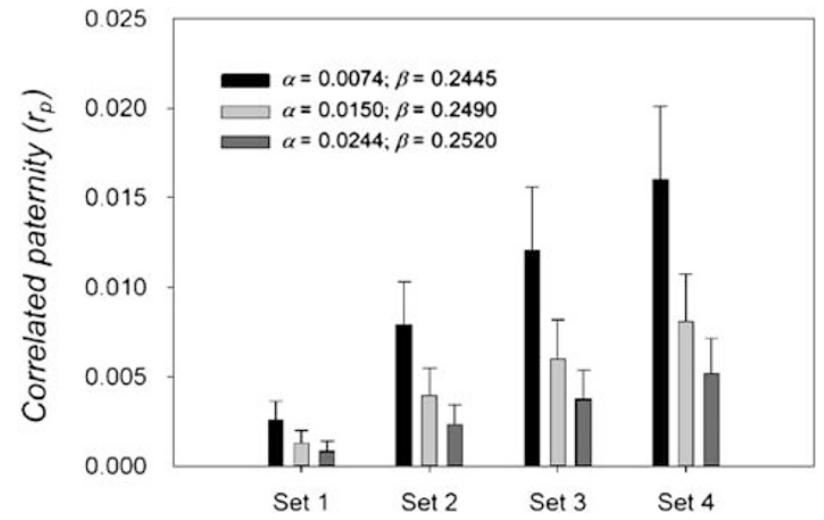

Figure 4 Correlated mating $\left(r_{\mathrm{p}}\right)$ estimates based on progeny arrays from 61 mother trees (average and s.d. of 1000 runs) in different simulated scenarios: (set 1) only restricted pollen dispersal effects are considered; scale $(\alpha)$ and shape $(\beta)$ parameters of the dispersal kernels used are also given; (set 2) join effects of restricted pollen dispersal and unequal male fertility are considered; (set 3) the effects of phenological differences are added to the model by simply considering phenological overlapping between pairs of trees and (set 4) explicit simulation of number of female flowers available for mating in a given day of the flowering period is included in the model, alongside with the effects of restricted pollen dispersal and unequal male fertility (see further details in the text).

et al., 1987) and Picea enelmannii (Shea, 1987), but not for P. jeffreyi (Furnier and Adams, 1986) and Abies lasiocarpa (Shea, 1987). Experimental data and numerical simulations suggest that increased selfing would only be observed in stands with very low density (below 20 trees per hectare in P. sylvestris; Robledo-Arnuncio et al., 2004a) and that among-population variation in outcrossing rates is limited in conifers (see $\mathrm{O}^{\prime}$ Connell et al., 2006, for P. glauca).

A remarkable result of our study, given frequent reports of correlation between stand and mating variables (for example, El-Kassaby and Jaquish, 1996), is that most of the variation in maritime pine mating parameters was found at the individual-tree level (99-100\% of the variance). Although a substantial portion of this variation is unavoidably due to the high estimation errors typically suffered by mating system estimators at this level of analysis, we found that multi- and singlelocus outcrossing rates were correlated with tree size (DBH and HT) and crown variables (height at crown base and ellipsoid surface). In addition, correlated paternity was correlated with different height variables (as summarized by PC2). The positive relationship between tree and crown size and outcrossing rates suggested that the proportion of outcrossed pollen reception might be enhanced in bigger trees with ample crowns, decreasing selfing rates. However, O'Connell et al. (2004) observed that outcrossing rates decreased with increasing tree height in four populations of Thuja plicata. This variety of results emphasizes the idea that tree size, apart from directly affecting outcrossing rates through increasing flower exposition to the pollen cloud, may also be a gauge for other factors affecting mating patterns, such as reproductive effort or tree social position within the stand (Burczyk et al., 1996; González-Martínez et al., 2006). There is growing evidence showing that the relative position of the crown 
of trees to neighboring woody plants (of the same or different species) might have a higher influence on mating patterns than absolute tree attributes, such as HT and diameter at breast height. For instance, OddouMuratorio et al. (2005) found that dominant-stand and edge trees had male fecundities double of those of suppressed trees and García et al. (2005) reported in Prunus mahaleb a trend for outcrossing rates to decrease in dense patches where mother trees are dominated by other woody species. Similar arguments might apply to other mating system features, such as correlated mating, for which a significant negative correlation with height variables has been found in this study.

Pollen dispersal kernels (fitted using TwoGener and KinDist indirect methods) estimated relatively large average effective dispersal distances (78.4 and $174.4 \mathrm{~m}$ in Talayuelas and Landete, respectively, and $111.9 \mathrm{~m}$ in a pooled analysis of the three stands) and followed leptokurtic distributions (shape parameter, $\beta$, of 0.2445 in Talayuelas, 0.2520 in Landete and 0.2229 in the pooled analysis) in Mediterranean maritime pine. Similar pollen dispersal distances have been reported for other windpollinated temperate trees, such as pines $(135 \mathrm{~m}$ for P. sylvestris, Robledo-Arnuncio and Gil, 2005; $140 \mathrm{~m}$ for $P$. flexilis, Schuster and Mitton, 2000) or European ashes (119-147 $\mathrm{m}$ for Fraxinus angustifolia and F. excelsior; Gérard et al., 2006). Oddou-Muratorio et al. (2005) reported pollen dispersal distances of over $500 \mathrm{~m}$ in Sorbus torminalis, an animal-pollinated tree, but these high values probably responded to the very low densities $(\sim 0.4$ trees per hectare, compared to $\sim 900-1000$ trees per hectare in maritime pine) and scattered distribution of the species. Our findings also agree with estimates of effective pollen immigration into natural populations of wind-pollinated species, which is usually large, especially when studied in sample plots located within larger continuous forest stands (Burczyk et al., 2004). In the particular case of maritime pine, a minimum pollen immigration rate of $36.5 \%$ has been found in a nonisolated seed orchard located in Mimizan, southwestern France (Plomion et al., 2001).

The numerical simulations conducted showed that neither restricted pollen dispersal (following the bestfitting, fat-tailed dispersal kernels) nor differences in male fertility or flowering asynchrony, alone or in combination, were able to explain the levels of correlated paternity (or effective number of fathers, its inverse) observed. These results contrast with common expectations of these variables explaining most of the variation found in mating system parameters of temperate forest trees. In dense pine stands, distance-dependent mating success has a large impact on the effective number of fathers but does not seem to be the single factor causing increased correlated paternity. It is more plausible that distance effects act simultaneously with differences in male fertility and phenology. Nevertheless, judging by the simulations conducted, differences in reproductive effort (resulting in a coefficient of variation in mating success of $\sim 129 \%$ ) or normally observed levels of phenological asynchrony (CV of $\sim 65-99 \%$ ) alongside with restricted pollen dispersal are not enough to explain the correlated mating levels observed in Mediterranean maritime pine stands. Thus, other factors not included in the simulations, such as within-stand social position (dominant vs suppressed trees, as discussed above) could play a more relevant role.
An inverse relationship between density and dispersal distance is well documented for animal-pollinated trees (Burczyk et al., 2002; White et al., 2002) and for different wind-pollinated conifers (El-Kassaby and Jaquish, 1996; Dyer, 2002; Robledo-Arnuncio et al., 2004a). A common explanation of this fact is that a reduction in canopy density can enhance within-stand air movements (Okubo and Levin, 1989) and pollen being carried over larger distances (Di-Giovanni and Kevan, 1991; Lindgren et al., 1995). However, the pollen dispersal distances obtained in our study for Talayuelas $(\delta=174.4 \mathrm{~m}$ and 1068 trees per hectare) and Landete $(\delta=78.4 \mathrm{~m}$ and 810 trees per hectare) were not consistent with this hypothesis. Talayuelas had a higher average height than Landete and one possible explanation may be that taller trees disperse pollen over larger distances, as suggested by Di-Giovanni and Kevan (1991). Alternatively, differences in average pollen dispersal distance between stands might simply respond to an (unknown) parameter estimation error associated with the indirect method used, as discussed below.

First, two potential sources of error in the indirect estimation of the dispersal kernels are that, (1) both stands, Talayuelas and Landete, have high densities (over 800 trees per hectare) and that (2) the sample size in Landete was small (only 11 mother trees, with no significant association between inter-female correlated paternity and distance). These two factors may be translated into a large estimation variance (RobledoArnuncio et al., 2006). Second, inter-female distance classes were differently represented within each of the two populations (Figure 2), mainly at short distances, which might have resulted in different kernel fits even if the actual dispersal pattern were the same for both populations. Although the distribution of inter-female distances is not, in theory, expected to affect indirect estimates of pollen dispersal strongly (Austerlitz and Smouse, 2001; Robledo-Arnuncio et al., 2006), testing the real importance of this effect would require a more intensive and homogenous sampling of nearby mothers in the two populations. Note, however that individual (within mother tree) correlated paternity estimates, as opposed to among-mother correlated paternity rates (on which our dispersal kernel estimates were based), cannot be expected to depend on inter-female distance, since they are determined by population density and other population parameters and not by the spatial distribution of sampled mothers relative to each other.

Overall, despite large amounts of pollen flow in dense Mediterranean maritime pine stands, some marked effects of single-tree attributes on mating features have been found in this study, mainly related to tree size and crown variables. In addition, differences in male reproductive effort and phenological overlapping might have acted simultaneously with tree social position (and other factors) and increased variability on observed single-tree mating patterns. Nevertheless, mating system features were fairly constant across different populations and stands within a broad provenance region, validating current practices based on relatively large breeding and conservation units. A main result of this study is that the gathering of mating system knowledge in the implementation of a conservation-oriented forest management policy has to rely on single-tree scale processes and local neighborhoods more than on regional patterns. We have 
also provided estimates of pollen dispersal kernels, with consistently leptokurtic dispersal across populations pointing at the need for broader buffer areas (probably of thousands of meters) to prevent pollen immigration from commercial plantations into genetic reserves. Pollen dispersal kernel parameterization will also be useful to build explicit simulation models of range expansion and response to global climate change in maritime pine. Finally, relatively low selfing and correlated paternity rates, along with large average pollen dispersal distances, suggest a limited importance of the spatial location of trees in the prevention of inbreeding in conservation plantations and breeding programs, at least at the moderate-high population densities investigated in this study.

\section{Acknowledgements}

We thank F Austerlitz for valuable comments on the study design and OJ Hardy for providing basic scripts that were used (heavily modified) to conduct the numerical simulations. Thanks are extended to C Ordóñez and A Bravo, and JC Santana and P Recio, for field and laboratory assistance, respectively, to three anonymous reviewers for valuable criticism and to PC Grant for the English grammar review. AI de Lucas was supported by a PhD scholarship from the Universidad de Valladolid, SC González-Martínez by a Ramón y Cajal fellowship RC02-2941 and JJ Robledo-Arnuncio by a Marie Curie Intra-European Fellowship within the sixth European Community Framework Programme. The work was financed by CICYT AGL2001-1780 and AGL2004-07094-C02-02 projects.

\section{References}

Adams WT, Burczyk J (2000). Magnitude and Implications of Gene Flow in Gene Conservation Reserves. CSIRO Publishing: Collingwood, Australia. pp 215-224.

Alía R, Gil L, Pardos JA (1995). Performance of 43 Pinus pinaster provenances on 5 locations in Central Spain. Silvae Genet 44: 75-81.

Alía R, Moro J, Denis JB (1997). Performance of Pinus pinaster provenances in Spain: interpretation of the genotype by environment interaction. Can J Forest Research 27: 1548-1559.

Austerlitz F, Dick CW, Dutech C, Klein EK, Oddou-Muratorio S, Smouse PE et al. (2004). Using genetic markers to estimate the pollen dispersal curve. Mol Ecol 13: 937-954.

Austerlitz F, Smouse PE (2001). Two-generation analysis of pollen flow across a landscape. II. Relation between $\mathrm{Fft}$, pollen dispersal and interfemale distance. Genetics 157: 851-857.

Austerlitz F, Smouse PE (2002). Two-generation analysis of pollen flow across a landscape. IV. Estimating the dispersal parameter. Genetics 161: 355-363.

Boshier DH (2000). Mating systems. In: Boyle T, Boshier D, Young A (eds). Forest Conservation Genetics: Principles and Practice. CSIRO Publishing: Collingwood, Australia, 350pp.

Bucci G, González-Martínez SC, Le Provost G, Plomion C, Ribeiro MM, Sebastiani F et al. (2007). Range-wide phylogeography and gene zones in Pinus pinaster Ait. revealed by chloroplast microsatellite markers. Mol Ecol 16: 2137-2153.

Burczyk J, Adams WT, Moran GF, Griffins AR (2002). Complex patterns of mating revealed in a Eucalyptus regnans seed orchard using allozyme markers and the neighbourhood model. Mol Ecol 11: 2379-2391.
Burczyk J, Adams WT, Shimizu JY (1996). Mating patterns and pollen dispersal in a natural knobcone pine (Pinus attenuata Lemmon.) stand. Heredity 77: 251-260.

Burczyk J, DiFazio SP, Adams WT (2004). Gene flow in forest trees: how far do genes really travel? Forest Genet 11: $1-14$.

Burdon JJ, Jarosz AM, Brown AHD (1988). Temporal patterns of reproduction and outcrossing in weedy populations of Echium plantagineum. Biol J Linn Soc 34: 81-92.

Chagné D, Chaumeil P, Ramboer A, Collada C, Guevara A, Cervera MT et al. (2004). Cross-species transferability and mapping of genomic and cDNA SSRs in pines. Theor Appl Genet 109: 1204-1214.

Chambel R (2006). Variabilidad adaptativa y plasticidad fenotípica en procedencias de pinos 8 ibéricos. PhD dissertation, Universidad Politécnica de Madrid, Madrid.

Degen B, Bandou E, Caron H (2004). Limited pollen dispersal and biparental inbreeding in Symbhonia globulifera in French Guiana. Heredity 93: 585-591.

Derory J, Mariette S, González-Martínez SC, Chagné D, Madur D, Gerber $S$ et al. (2002). What can nuclear microsatellites tell us about maritime pine genetic resources conservation and provenance certification strategies? Ann Forest Sci 59: 699-708.

Di-Giovanni F, Kevan PG (1991). Factors affecting pollen dynamics and its importance to pollen contamination: a review. Can J Forest Research 21: 1155-1170.

Dow BD, Ashley MV (1998). Factors influencing male mating success in bur oak, Quercus macrocarpa. New Forest 15: 161-180.

Doyle JJ, Doyle JL (1990). Isolation of plant DNA from fresh tissue. Focus 12: 13-15.

Dyer RJ (2002). Contemporary pollen movement in shortleaf pine, Pinus echinata Mill. PhD dissertation, University of Missouri, St Louis, MO.

El-Kassaby YA, Dunsworth BG, Krakowski J (2003). Genetic evaluation of alternative silvicultural systems in coastal montane forests: western hemlock and amabilis fir. Theor Appl Genet 107: 598-610.

El-Kassaby YA, Jaquish B (1996). Population density and mating pattern in western larch. J Hered 87: 438-443.

Farris MA, Mitton JB (1984). Population density, outcrossing rate, and heterozygote superiority in ponderosa pine. Evolution 38: 1151-1154.

Franceschinelli EV, Bawa KS (2000). The effect of ecological factors on the mating system of a South American shrub species (Helicteres brevispira). Heredity 84: 116-123.

Furnier GR, Adams WT (1986). Mating system in natural populations of Jeffrey pine. Am J Bot 73: 1008-1022.

García C, Arroyo M, Godoy A, Jordano P (2005). Mating patterns, pollen dispersal, and the ecological maternal neighbourhood in a Prunus mahaleb L. population. Mol Ecol 14: $1821-1830$.

Gérard PR, Klein EK, Austerlitz F, Fernández-Manjarrés JF, Frascaria-Lacoste N (2006). Assortative mating and differential male mating success in an ash hybrid zone population. BMC Evol Biol 6: 96.

Glémin S, Bazin E, Charlesworth D (2006). Impact of mating systems on patterns of sequence polymorphism in flowering plants. Proc $R$ Soc B 273: 3011-3019.

González-Martínez SC, Burczyk J, Nathan R, Nanos N, Gil L, Alía R (2006). Effective gene dispersal and female reproductive success in Mediterranean maritime pine (Pinus pinaster Aiton). Mol Ecol 15: 4577-4588.

González-Martínez SC, Cervera MT, Martínez-Zapater JM, Gil L, Alía R (2002). Seed gene flow and fine-scale structure in a Mediterranean pine (Pinus pinaster Ait.) using nuclear microsatellite markers. Theor Appl Genet 104: 1290-1297.

Griffin CAM, Eckert CG (2003). Experimental analysis of biparental inbreeding in a self-fertilizing plant. Evolution 57: 1513-1519. 
Hardy OJ, González-Martínez SC, Colas B, Fréville H, Mignot A, Olivieri I (2004). Fine-scale genetic structure and gene dispersal in Centaurea corymbosa (Asteraceae). II. Correlated paternity within and among sibships. Genetics 168: 1601-1614.

Holsinger KE (2000). Reproductive systems and evolution in vascular plants. Proc Natl Acad Sci USA 97: 7037-7042.

Klein EK, Lavigne C, Gouyon P-H (2006). Mixing of propagules from discrete sources at long distance: comparing a dispersal tail to an exponential. BMC Ecol 6: 1-12.

Knowles P, Furnier GR, Aleksiuk MA, Perry DJ (1987). Significant levels of self-fertilization in natural populations of tamarack. Can I Bot 65: 1087-1091.

Lindgren D, Paule L, Shen XH, Yazdani R, Segerström U, Wallin JE et al. (1995). Can viable pollen carry Scots pine genes over long distances? Grana 34: 64-69.

Miguel-Pérez I, González-Martinez SC, Alía R, Gil L (2002). Growth phenology and mating system of maritime pine (Pinus pinaster Aiton) in central Spain. Invest Agr: Sist Recur For 11: 195-204.

Murawski DA, Gunatilleke IAUN, Bawa KS (1994). The effects of selective logging on inbreeding in Shorea megistophylla (Dipterocarpaceae) from Sri Lanka. Conserv Biol 8: 997-1002.

Nanos N, González-Martinez SC, Bravo F (2004). Studying within-stand structure and dynamics with geostatistical and molecular marker tools. Forest Ecol Manag 189: 223-240.

O'Connell LM, Mosseler A, Rajora OP (2006). Impacts of forest fragmentation on the mating system and genetic diversity of white spruce (Picea glauca) at the landscape level. Heredity 97: 418-426.

O'Connell LM, Russell J, Ritland K (2004). Fine-scale estimation of outcrossing in western redcedar with microsatellite assay of bulked DNA. Heredity 93: 443-449.

Oddou-Muratorio S, Klein EK, Austerlitz F (2005). Real-time patterns of pollen flow in the wildservice tree, Sorbus torminalis (L.) Crantz. II. Spatial patterns of pollen flow and variance in male reproductive success inferred from parentoffspring. Mol Ecol 14: 4441-4452.

Okubo A, Levin SA (1989). A theoretical framework for data analysis of wind dispersal of seed and pollen. Ecology 70: 329-338.

Plomion C, LeProvost G, Pot D, Vendramin GG, Gerber S, Decroocq $S$ et al. (2001). Pollen contamination in a maritime pine polycross seed orchard and certification of improved seeds using chloroplast microsatellites. Can J Forest Research 31: $1816-1825$.

Ritland K (2002). Extensions of models for the estimation of mating systems using $n$ independent loci. Heredity 88: 221-228.

Robledo-Arnuncio JJ, Alía R, Gil L (2004a). Increased selfing and correlated paternity in a small population of a predominantly outcrossing conifer, Pinus sylvestris. Mol Ecol 13: 2567-2577.

Robledo-Arnuncio JJ, Austerlitz F, Smouse PE (2006). A new indirect method of estimating the pollen dispersal curve, independently of effective density. Genetics 173: 1033-1045.
Robledo-Arnuncio JJ, Gil L (2005). Patterns of pollen dispersal in a small population of Pinus sylvestris L.) revealed by total-exclusion paternity analysis. Heredity 94: 13-22.

Robledo-Arnuncio JJ, Smouse PE, Gil L, Alía R (2004b). Pollen movement under alternative silvicultural practices in native populations of Scots pine (Pinus sylvestris L.) in central Spain. Forest Ecol Manag 197: 245-255.

Schoen DJ, Brown AHD (1991). Intraspecific variation in population gene diversity and effective population size correlates with the mating system in plants. Proc Natl Acad Sci USA 88: 4494-4497.

Schuster WSF, Mitton JB (2000). Paternity and gene dispersal in limber pine (Pinus flexilis James). Heredity 84: 348-361.

Shea KL (1987). Effects of population structure and cone production on outcrossing rates in Engelmann spruce and subalpine fir. Evolution 41: 124-136.

Smouse P, Dyer RJ, Westfall RD, Sork VL (2001). Two-generation analysis of pollen flow across a landscape. I. Male gamete heterogeneity among females. Evolution 55: 260-271.

Smouse P, Meagher TR, Kobak CJ (1999). Parentage analysis in Chamaelirium luteum (L.) Gray (Liliaceae): why do some males have higher reproductive contributions? J Evol Biol 12: 1069-1077.

Smouse P, Robledo-Arnuncio JJ (2005). Measuring the genetic structure of the pollen pool as the probability of paternal identity. Heredity 94: 640-649.

Smouse P, Sork VL (2004). Measuring pollen flow in forest trees: an exposition of alternative approaches. Forest Ecol Manag 197: 21-38.

Sork VL, Smouse PE (2006). Genetic analysis of landscape connectivity in tree populations. Landscape Ecol 21 : 821-836.

Tapias R, Climent J, Pardos JA, Gil L (2004). Life histories of Mediterranean pines. Plant Ecol 171: 53-68.

Torres AM, Weeden NF, Martín A (1993). Linkage among isozyme, RFLP and RAPD markers in Vicia faba. Theor Appl Genet 93: 613-617.

Tufto J, Engen S, Hindar K (1997). Stochastic dispersal processes in plant populations. Theor Popul Biol 52: 16-26.

Van Treuren R, Bulsma R, Ouborg NJ, Kwak MM (1994) Relationships between plant density, outcrossing rates and seed set in natural and experimental populations of Scabiosa columbaria. J Evol Biol 7: 287-302.

Verdú M, González-Martínez SC, Montilla AI, Mateu I, Pannel JR (2006). Ovule discounting in an outcrossing, cryptically dioecious tree. Evolution 60: 2056-2063.

Wasieliwska M, LKlemm M, Burczyk J (2005). Genetic diversity and mating system of Scots pine plus trees. Dendrobiology 53 : 57-62.

White GM, Boshier DH, Powell W (2002). Increased pollen flow counteracts fragmentation in a tropical dry forest: an example from s humilis Zuccarini. Proc Natl Acad Sci USA 99: 2038-2042.

Wolff K, Frisco B, Van Damme JMM (1988). Outcrossing rates and male sterility in natural populations of Plantago coronopus. Theor Appl Genet 76: 190-196.

Supplementary Information accompanies the paper on Heredity Web site (http://www.nature.com/hdy) 